\title{
The Practical Logic and Countermeasures of Community Home-based Elderly Care Service Under the Dimension of Innovative Big Data
}

\author{
Shi Jing \\ School of Culture and Media, Central University of Finance and Economics, Beijing, China
}

Email address:

shijing0707@163.com

To cite this article:

Shi Jing. The Practical Logic and Countermeasures of Community Home-based Elderly Care Service Under the Dimension of Innovative Big Data. Humanities and Social Sciences. Vol. 8, No. 3, 2020, pp. 78-85. doi: 10.11648/j.hss.20200802.15

Received: May 27, 2020; Accepted: June 10, 2020; Published: June 17, 2020

\begin{abstract}
Under the background of accelerating the integrative development of big data technology, fiscal finance, and public services to the community home-based care industry model, with the continuous acceleration of China's social aging process, the government uses public finance to provide a basic community home care services for elderly residents. This paper analyzes the development status of community home care services, analyzes the root sources of the problems on insufficient supply, imbalance and unequalization of care services caused by China's financial system, and proposes a reasonable division of financial and administrative rights for community home care services, optimize the expenditure structure of public finance for community home-based elderly care, improve the use efficiency of financial funds for community home-based elderly care services, effectively supervise financial transfer payments, introduce the market mechanism to cultivate the policies and suggestions of the market main body of community home-based elderly care services. The state formulates fiscal policies and laws and regulations to strongly support the construction of community home-based care services. Promote the fiscal system reform of community elderly care service industry and cultivate the market main body of community home-based elderly care service. Develop a professional, branded and chained community home-based care service system, accelerate the healthy development of community home-based elderly care, and achieve good elderly care.
\end{abstract}

Keywords: Fiscal System, Community Home-Based Care, Endowment Pattern

\section{Introduction}

Since the State Council issued the "Outline of Action for the Development of Big Data", it will achieve the perfect network sharing of public data and government information systems, giving priority to supporting the application of government data in urban construction and community home-based care services, and accelerating big data technology and fiscal finance and public services in the integrative development of the community home-based care industry modal, the development of human society has entered the era of networked innovation big data of interconnectivity. According to the definition of public goods by Economist Paul A Samuelson, community home-based care (also known as community help the elderly and home-based community care) services belong to quasi-public goods which is a positive externality, non competitive and non exclusive basic public service provided by the government to community residents, covering the reconstruction and expansion of hardware facilities in the community for home-based elderly care, the promotion of employment rate in the community, the provision of high-quality diagnosis and treatment services and healthy elderly entertainment life, and the improvement of the level of old-age care services and the construction of public utilities with service skills, etc. Since community home care for the elderly is a service project based on the government's public finances, to a certain extent, it will be restricted by the financial system's own factors, which will affect the development of community home care services. This article first sorts out the status quo of the development of community home-based care services, then analyzes the influencing factors of the division of responsibilities in the aspects of intergovernmental fiscal authority and expenditure to promote the development of the current community home care mode, 
and finally puts forward policy suggestions for developing and improving the matching community home-based elderly care service system.

\section{The Development Status of Community Home-based Elderly Care Service in China}

In China, the community home-based elderly care service belongs to the non economic public goods provided by the government finance. At present, it mainly relies on the local government to provide funds to support the construction of community elderly care public facilities and medical services. Since the object of community home care service is the elderly residents who can take care of themselves or have partial self-care ability in the community, it is determined that the service has a weak liquidity to attract capital and it is easy to reduce the supply power and enthusiasm of local governments [1]. It is estimated that by 2030 , the total population of China will reach its peak, and the elderly population over the age of 60 will account for nearly $25 \%$ of the population, which will be the world's most aging country [2]. The following figure (unit: 100 million) shows the basic growth trend of the elderly population in China. The horizontal axis represents the year and the vertical axis represents the number of the elderly population.

\section{The Elderly Population (100 million people)}

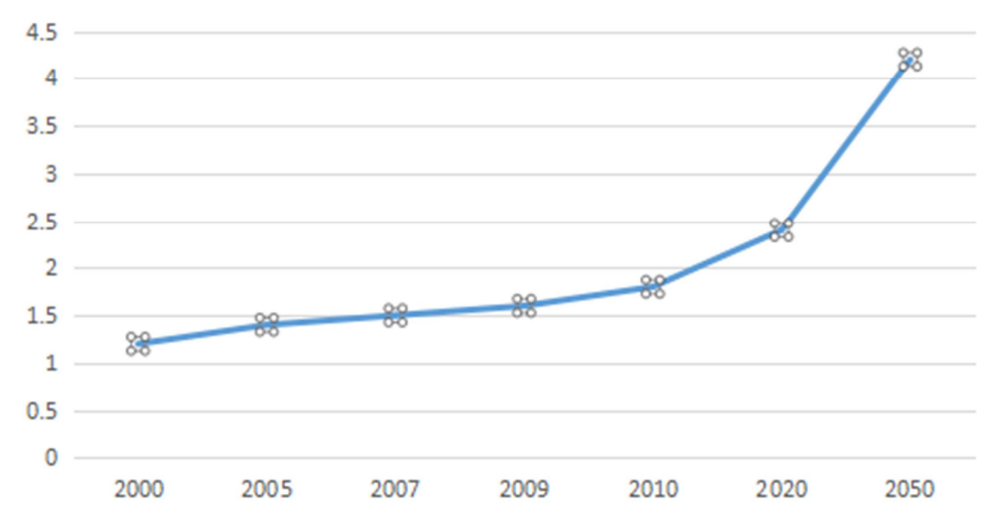

Figure 1. The Basic Growth Trend of the Elderly Population in China.

It can be seen from figure 1 that the base number of the elderly population in China is relatively large. In recent years, the number of the elderly population has shown a trend of rapid increase in total, and the aging population has increased the demand for care services [3]. In China, the family planning policy continues to have more and more "four - two - one" families. With the increase of intergenerational differences, the traditional pension mode has been unable to meet the needs of the elderly in many aspects. As a basic public service provided by the government, community home-based pension has become an ideal way of old-age care. In the Government Work Report of our country, it has always been advocated that a new comprehensive "home-based, community-based, and institution supplemented" care service mode should be established. The central government will use the new form of "replacing compensation with awards" to distribute special public welfare funds to further improve the reform of China's pension service system [4].

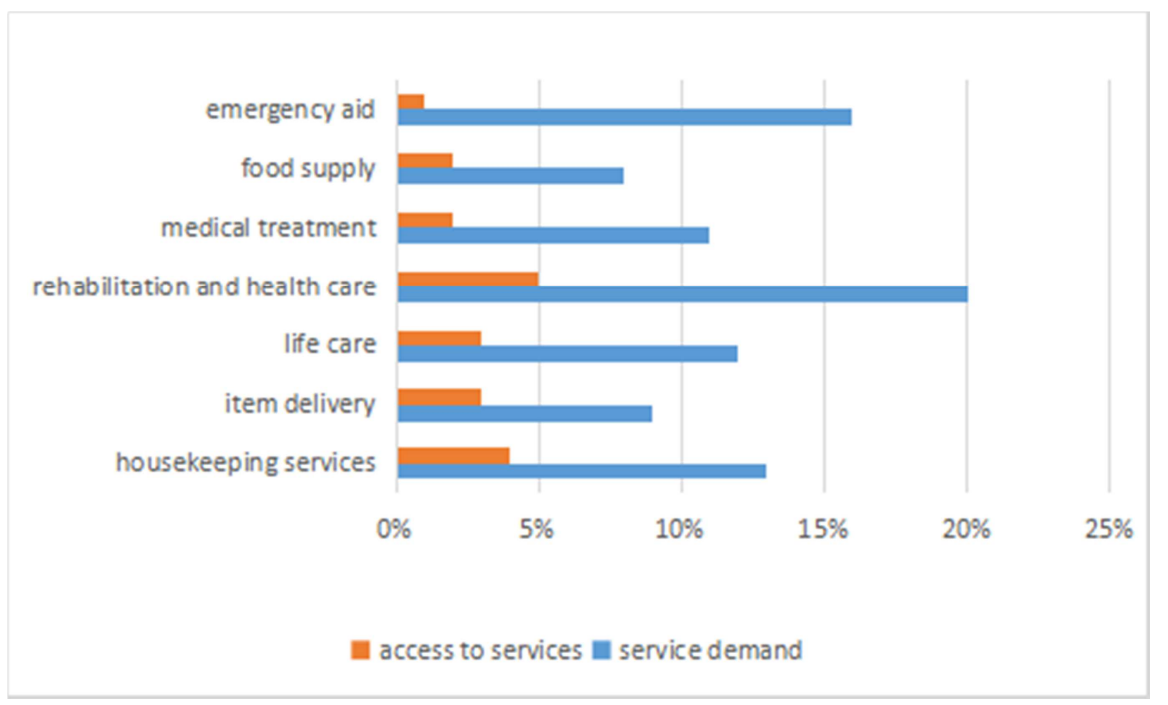

Figure 2. Demand for Community Home Care Services and Services Received. 
Figure 2 is a sample survey of "the demand and the obtained service of community home-based pension service" for the elderly in China. According to the seven pension service items provided by community home-based pension, namely, domestic service, goods distribution, life care, rehabilitation and health care, medical treatment, catering supply and emergency assistance, the supply and demand of community home-based pension service in China is unbalanced, and the actual pension enjoyment rate of the elderly is far less than their expectation rate of pension demand. The survey data fully shows that the total supply level of community home-based elderly care service in China is less than the demand. The demand of the elderly for the ideal community home-based elderly care service is increasing, which is in contradiction with the low coverage of the community home-based elderly care service in reality. The reason why the form of community home-based pension is more suitable for the elderly is mainly based on the following two reasons. On the one hand, the cost of medical services provided by the community home-based pension mode is relatively low, which involves a wide range, and the practical and flexible service. When the elderly get some common diseases that are not serious, diagnosis and treatment can be carried out in the community first to avoid the pain of long-term alienation from their relatives caused by the elderly's direct hospitalization. Community home-based elderly care service mode enables the elderly to obtain a sense of belonging and comfortable security. On the other, due to the socialized function of the community, the elderly often regard the community as a platform for socialized communication, which can enhance the communication and exchange between the elderly and new and old friends, social organizations, not only effectively relieve the psychological loneliness of the elderly, but also greatly reduce the nursing pressure of the elderly children.

Home-based care, institution endowment and community home-based care are the three common old-age care modes in China. Table 1 compares the eleven aspects of elderly care, such as beneficiaries of old-age care, national policies, government roles, old-age subjects, old-age resources, old-age wishes, sources of spiritual comfort, convenience, safety, economy and beneficiaries.

Table 1. Comparison of Home-based Care Models for families, institutions and communities.

\begin{tabular}{|c|c|c|c|}
\hline & family supporting & institution endowment & community home-based elderly care \\
\hline beneficiaries & $\begin{array}{l}\text { old people whose children are } \\
\text { able to take care of }\end{array}$ & $\begin{array}{l}\text { special care for the elderly and the } \\
\text { elderly with better economic conditions }\end{array}$ & all the aged \\
\hline national policies & $\begin{array}{l}\text { the state subsidizing part of } \\
\text { the elderly }\end{array}$ & $\begin{array}{l}\text { government investment and } \\
\text { construction }\end{array}$ & $\begin{array}{l}\text { national finance unifying the burden in the form of } \\
\text { government procurement }\end{array}$ \\
\hline government roles & no & leaders, investors and service providers & leader and investor \\
\hline equality & equal starting point & unequal & equal starting point, process and result \\
\hline equality & family & government and society & $\begin{array}{l}\text { state, government, society, community, family, public } \\
\text { sector, for-profit sector and non-profit organizations }\end{array}$ \\
\hline equality & $\begin{array}{l}\text { family providing resources for } \\
\text { the aged, and the resources for } \\
\text { the aged insufficient }\end{array}$ & $\begin{array}{l}\text { pension resources provided by pension } \\
\text { institutions, and sufficient }\end{array}$ & $\begin{array}{l}\text { integrate the comprehensive endowment resources of } \\
\text { society, family and community, with sufficient } \\
\text { endowment resources }\end{array}$ \\
\hline wishes & $\begin{array}{l}\text { family relatives, friends and } \\
\text { neighbors }\end{array}$ & $\begin{array}{l}\text { Not in line with traditional Chinese } \\
\text { pension wishes and choices }\end{array}$ & $\begin{array}{l}\text { living at home or in a familiar community in line with the } \\
\text { traditional wishes and choices of the elderly }\end{array}$ \\
\hline $\begin{array}{l}\text { source of spiritual } \\
\text { consolation }\end{array}$ & $\begin{array}{l}\text { family relatives, friends and } \\
\text { neighbors }\end{array}$ & $\begin{array}{l}\text { service personnel and social volunteers } \\
\text { of pension institutions }\end{array}$ & $\begin{array}{l}\text { family relatives, community pension service personnel, } \\
\text { community members, neighbors and social volunteers }\end{array}$ \\
\hline safety & weaker & strong & centered \\
\hline economy & $\begin{array}{l}\text { The strongest economy and } \\
\text { depending on the family }\end{array}$ & $\begin{array}{l}\text { the weakest economy and highest } \\
\text { expense }\end{array}$ & $\begin{array}{l}\text { economically centered, using community and family } \\
\text { resources }\end{array}$ \\
\hline
\end{tabular}

This paper makes a comparative analysis on the following four aspects of the three pension models in Table 1. First, when choosing the two models of home-based elderly care and institution endowment, the government alone can not meet and guarantee the elderly care service of the whole society, and thus there is a loss of principle of equality and fairness. The community home-based pension mode organically combines two forms of home-based elderly care and institution endowment, and becomes a new socialized pension form. According to the principle of equality and fairness, it effectively uses the government's financial funds, integrates the social, community and family supporting resources for the aged, makes the elderly in the whole society become the beneficiaries, and meanwhile improves the credibility of the government. Second, the construction of facilities in institutional endowment mainly depends on the government's supporting funds. This way of old-age care is only applicable to some elderly people with good economic conditions and special care. They receive professional elderly care provided by nursing institutions for the aged by paying a high monthly pension service fee. The service subject of community pension has realized diversification. It is the cooperation among the government, market, society and non-governmental organizations to meet and ensure that each elderly can enjoy the convenient pension services provided by the government financial pension funds. Third, compared with family-based elderly care and institution endowment, community home-based pension is easier to meet the various 
pension and consumption needs of the elderly, make up for the lack of traditional institutional pension and family supporting the aged, and become the best way to solve the annuity problem in China. Community home-based pension not only changes the government's management mode of "all inclusive" but also expands the radiation of the government's provision of public services for the elderly to ensure that the elderly can enjoy a safe and comfortable old age [5]. Fourth, from the equalization of public services provided by the government to analyze the above table, on the one hand, the starting point of community home-based pension service is equal. In the community home-based care model, all the elderly have the same rights, to ensure that every elderly can enjoy these caring services for the elderly, and the starting point is equal. On the other, the process of community home-based care service is equal. The community home-based elderly care public service with the government as the main body can be basically provided to the elderly in the whole society without any difference, and it can equally open high-quality elderly care services for each elderly. In addition, the adoption of community home-based care is also conducive to relieve the physical and psychological pressure of the elderly carers and meet the basic requirements of the equalization of community-based care services, while the two modes of institutional and family care obviously do not have these advantages.

\section{Logical Consideration of the Problems in the Community Home Care Model in China}

With the rapid development of China's aging population, urban and township community home care services are increasingly paid attention to by the whole society. However, while China's financial system has brought rapid economic growth, it has also become a source of inefficiency in the provision of community home care services in China. It is not difficult to see that China's fiscal system is based on the appointment system of the central or higher levels of government. The current status of the appointment system, the weak mobility of the population, and the scarcity of capital factors have caused local governments to show insufficient supply for community home care needs [6]. In China, the initial establishment of the community home pension system has not been for long, various functions are not yet perfect. The community pension service mainly faces the following four problems that must be resolved.

1. China's political and economic system and performance appraisal system to a certain extent lead to the shortage and imbalance of community home-based pension service supply. The main reasons are as follows. First, our country belongs to the centralized fiscal system, which allows the central government to directly decide on and administer the appointment, removal and performance appraisal of subordinate officials. The Chinese fiscal decentralization has changed the proper public expenditure structure of local governments. On the one hand, China's fiscal decentralization system is to encourage local governments at all levels to increase the proportion of financial expenditure on infrastructure construction, which is prone to bias between the public service supply behavior invested by local governments and the actual demand preference of local residents for community home-based elderly care services [7]. On the other, in the process of acting for the central government to provide services for community home care for the elderly, the local governments have reduced the financial investment of the community home care service due to the fact that this investment cannot be quickly cashed into economic growth in the short term, resulting in the shortage and imbalance of the community home-based elderly care service supply [8]. Second, under the Chinese style fiscal decentralization system, local governments attach great importance to the expenditure on public administration and infrastructure, and neglect the expenditure on culture, education, science and health for community pension. Therefore, the allocation and use of these financial funds and financial expenditure by local governments are likely to result in the insufficient supply of community home-based care services, and the aspects where the government uses the financial public expenditure for community home-based elderly care services do not improve the supply of elderly care services. Third, the reasons for the absence of government functions and insufficient support for elderly care services are mainly reflected in the inadequate cultivation of non-profit organizations by the government, and the imperfect preferential policies for the private capital to invest in community home-based elderly care services.

2. The multi-dimensional financial decentralization indicators have caused local governments to have a certain impact on the allocation of diagnosis and treatment services for the elderly in the community, and weakened the information advantage of the elderly's demand preference. Generally, the local governments have the information advantage of the residents' preference for community home-based elderly care service in their jurisdictions. According to the preference information of the elderly, local governments effectively use financial funds to ensure that the supply structure of community home-based care services meets the needs of the community's elderly. In a comprehensive way of measurement, fiscal decentralization will improve the efficiency of medical service allocation. Specific to each indicator, for example, negative correlations are shown between the decentralization of local public administration and the efficiency of medical service in the allocation of community home-based pension, as well as between the ratio of local fiscal expenditure and income and the efficiency of medical service allocated in the community home-based pension. As the administrative power and the allocation of public resources in the local governments continue to increase, when the local governments can independently control the funds from the central transfer payment and the local own income and fiscal expenditure, the allocation efficiency that this situation has brought to the local community pension medical service is also negative influence, and which aggravates the current situation of insufficient supply. 
3. The central and local governments are weak for the supervision of fiscal transfer funds used for community home-based care services. The central and local governments are not very targeted at the fiscal subsidy system for the provision of community home-based care services, which subsidizes community home-based care medical services mostly in a way of special subsidies as the main form. These funds, in the process of payment links, subsidize some public hospitals and health and epidemic prevention system as well, so the beneficiaries of the subsidies are unclear. To a certain extent, it is difficult to supervise and manage the use of transfer payment funds for medical services in community home-based care services, and the reason is perhaps that the sum of money allocated to community home-based care services is so less. The fiscal system of China has forced governments at all levels to measure their achievements in terms of GDP. The greater the autonomy of fiscal expenditures controlled by local governments, the less conducive it is for them to make correct decisions about the supply of community-based medical care for the aged, and thus the supply of aged-care services is limited. Any of the central government's transfer payment funds or the local self-owned fiscal expenditures which are controlled and dominated by local governments at all levels has a negative impact on the efficiency of the allocations of community home-based care medical service.

4. The establishment of a community home-based care model lacks the introduction of a market mechanism, and the government bears too much responsibility. At present, the community home-based care model in China is a non-market operation mechanism. The management system only relies on a single government body. The government has almost taken all management responsibilities and has become a producer and an executor. It has not formed a benign market-oriented operation mode, which brings difficulties to the effective integration and absorption of social funds and information technology, and makes it difficult for the community home-based care service to develop rapidly and normally. At the same time, community home-based care for the elderly lacks normative policies and regulations, and also lacks the policies to support the operation of non-profit organizations, and the protection of the perfect old-age service system. In addition, the human, material and financial resources of the community home-based care service are very limited. It hasn't formed an independent and industrialized community-based care model. The way of capital investment is arbitrary, and the amount of capital investment is very unstable, which causes the imbalance between the supply and demand of community home-based elderly care, and restricts the breadth and quality of community-based elderly care service.

\section{Policy Suggestions on Promoting the Development of Community Home-based Elderly Care Service}

At present, the main way of providing care for the elderly in our country is community home-based care. This service provided by the central government and local governments to the elderly needs to be further improved. In order to better promote the construction of community home-based care services, the following policy recommendations and measures are proposed.

1. To a certain extent, increasing fiscal transfer payment and effective supervision can improve the supply of community home-based elderly care services. With the promotion of tax sharing system reform, the transfer payment from the central government to the local governments has gradually increased in intensity and scope. As local counties and towns and the backward areas have relied too much on transfer payment to provide supply for community home-based elderly care services, Transfer payment can play a positive role in improving the supply of old-age service facilities in local and backward areas. According to the transfer payment bringing about flypaper effect proposed by Oates W. in 1999, the effect of transfer payment on the increase of public expenditure on community home-based elderly care is much greater than that of local governments based on their own fiscal revenue [9]. At the same time, the central and local governments should strengthen the effective supervision of the transfer payment funds in the medical field of community home-based care for the aged, and improve the pertinence of the central and local governments to the fiscal subsidy system of community home-based care for the aged. By using more central special transfer payment funds to provide financing for the supply of community home-based elderly care services, organically integrate the central government's management, supervision, incentive mechanism with the demand preference information of elderly residents that local governments have mastered to improve the efficiency of community home-based elderly care service allocations and meet the needs of the elderly in the community. All of these are enough to show that increasing transfer payments and allowing local governments to allocate and use the special transfer funds for community home-based elderly care are an effective way to improve the supply and allocation efficiency of community home-based elderly care services, and the downward transfer payments from the central government are increasingly used in the field of expenditure for community home-based elderly care services. The downward transfer payment of the central government can promote the supply of community home-based elderly care services, which proves that it is necessary to return the centralized part of the central government's income to the local governments. In addition, redistributing the division of expenditure responsibilities between the central and local governments that deviate from the international experience, and integrating the local extra budgetary income into the budget management, local governments can let the extra budgetary income assist to bear the supply responsibility of community home-based elderly care services.

2. The state formulates fiscal policies and laws and regulations to strongly support the construction of community home-based care services. Experiences at home and abroad have shown that welfare undertakings are generally more 
difficult to operate independently. It is necessary to gather multiple forces to jointly create an operating mechanism that integrates public welfare, welfare services, and market-oriented operations. The fiscal policy plan issued by the State Council is to cultivate the community home-based elderly care service system into a professional, branded and chain-based elderly care industry cluster. The community home-based elderly care service industry will be included in the National People's Livelihood Project, and the investment of operation funds in the community home-based elderly care service, the construction of pension infrastructure and the conduct of comprehensive elderly care service will be increased. The government, enterprises and society jointly create a development fund for the community home-based pension service industry. The management of the fund is determined in the form of competition, and equity investment is encouraged to build a socialized community home-based care service system of "taking families as the core of the elderly care, communities as the support for the elderly, and professional services as the support for the elderly care, and serve the aged of their own families aiming at solving their difficulties in daily life", so as to create a good development environment for the elderly care service industry. The Ministry of Civil Affairs and the Ministry of Finance jointly with the central government fiscal support the exploration of the reform of "community home-based care services". Combined with the current situation, problems and key issues of home-based and community-based elderly care services in China, "7 + X" mode services are launched. We will establish a mechanism for government leaders and departments to coordinate supervision, management, guidance, and fund guarantee, screen the special elderly people and the elderly in trouble in their respective jurisdictions, clarify the key and difficult points of elderly care services, and make service plans. In order to gather the social strength, we'll build a multi effective supply pattern and service list system of community home-based elderly care service with social strength, and improve community home-based elderly care service facilities. In addition, relevant policies and laws should be formulated to guarantee the development of community home-based elderly care services. First, the community home-based pension service should be included in the national social security system, and the social pension security system should be further developed. Second, we'll build the foundation of institution for the community home-based elderly care service system, and establish the supervision, management and evaluation system of community home-based elderly care service. Third, we'll draw lessons from foreign and domestic community home-based pension pilot experiences, and make unified standard of community home-based pension as the basis of providing community home-based pension services. Fourth, we'll make laws as a reliable guarantee for the community home-based elderly care services.

3. Promote the fiscal system reform of community elderly care service industry and cultivate the market main body of community home-based elderly care service. There is no conclusion yet that the community home-based care belongs to the nature of pure welfare, or the nature of coexistence of welfare and profit-making. However, with the support of the central and local governments, this service introduces the market mechanism and welcomes the social non-governmental organizations to join in and provide certain forms of old-age security services. With the marketization of community home-based care services, it is reasonable choice of path to choose the development path of the industrialized community home-based care service. On the one hand, we should encourage social forces to join the community elderly care service industry, gradually remove the restrictions on the registered capital of community elderly care institutions, simplify the procedures of elderly care licensing, improve the management and operation of community elderly care, encourage private capital to join the restructuring of community home-based elderly care service industry, and develop a mixed ownership elderly care service industry. On the other, the central finance provides capital guidance to the community home-based pension service industry. The local governments, banks and enterprises co-finance to build the community home-based pension fund platform. According to the market-oriented operation mode, we should reasonably develop the community home-based elderly care and community elderly comprehensive services, create the elderly care service industry, and actively explore the rapid development mode of supporting the community home-based elderly care service industry by integrating the market and commercialization [10].

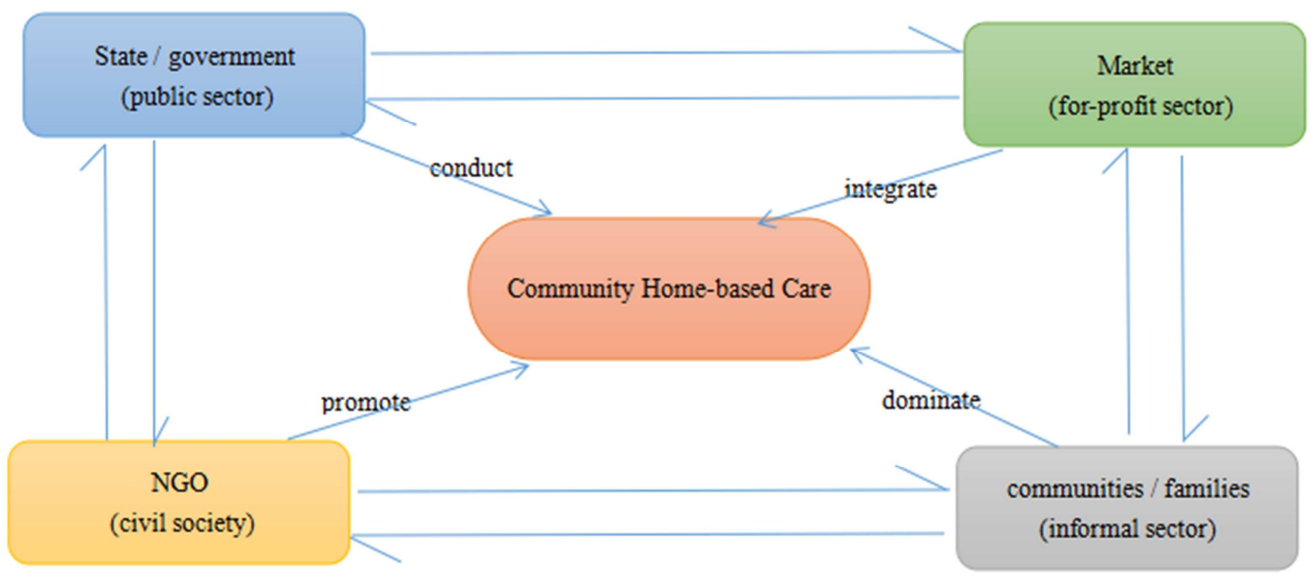

Figure 3. Framework of a Multi-dimensional Cooperation and Co-governance for Community Home-based Care for the Elderly. 
At present, the community home-based elderly care service mostly adopts the organization and management system of single subject mode, which is not conducive to the effective integration of existing resources, and needs to rely on external efforts to promote the rapid and healthy development of service system. The above Table 1 shows the realization of multiple cooperative and the community home-based elderly care co-governance mode of community home-based pension, which shows that the community home-based pension no longer only depends on the state and government, but also increases some public sectors, for-profit sectors and non-profit organizations, as well as families and communities. In the past, the government directly participated in the community home-based pension affairs, and has changed to play the role of macro coordination and policy conductor, and let the community home-based elderly care operate more independently. At the same time, the government also encourages the introduction of a large amount of social funds, the adoption of standardized human resource management system and forms of independent job competition in the public service industry to form stable, high-quality volunteer support old-age services to meet diverse needs for old-age care services [11]. At the same time, the government should create a policy environment that can attract private investment, introduce non-governmental organizations to manage community pension services, coordinate and integrate multiple interests to promote the operation of the market industrialization mode, and guide the community home-based pension to the orientation of organic combination of marketization, welfare and socialization developing sustainably and healthily.

4. Develop a professional, branded and chained community home-based care service system. With the rapid economic development, the absolute number of elderly people in our country has grown rapidly in recent years, and the proportion of elderly support and the level of specialization in elderly care are getting higher and higher. In response to the new mechanism of national and government support for innovation and entrepreneurship, all regions, industries and departments actively guide the development of small and medium-sized enterprises in community home-based elderly care service, improve their innovation ability with brand strategy, and build a community elderly care service industry cluster one by one with wide coverage, long industrial chain and economic benefits. Home-based care services platform for community elderly care is established based on the community, with "old-age care and Internet plus" as the concept, three-in-one combination of "communities +social workers + social organizations", establishment of "site-type community service station for the elderly", and alliance of "commonweal organizations + social organizations + commercial enterprises", which provides the community's elderly with comprehensive services such as "convenient life + medical treatment and health + security and salvation + spiritual comfort" in order to realize the path of "specialization + branding + chain + standardization" in community home-based elderly care services. A comprehensive old-age care industry service chain will be gradually formed, and a community old-age care model of "nursing homes without walls +15 -minute emergency circle + one-stop comprehensive services" will be constructed. The professionalization of elderly care service is reflected in the fact that the leaders, health administrators, helpers, carers and domestic workers of the community elderly care service departments must have certificates to work. They must first fully understand and master the health and family conditions of each elderly in the community, and these personnel who have received professional education and comprehensive training use professional knowledge and skills to carry out various services for the elderly. The communities can cooperate with some high-quality service industries that can meet the needs of the elderly, and the elderly in the community can buy pension services with compensation and low compensation. At the same time, chain service stations for the elderly can be established all over the country to benefit more elderly people who choose to live in the community for the aged [12].

5. Innovative big data and community home care "smart medical" services are organically integrated and developed. In 2015, the State Council issued the "Action Plan for the Development of Big Data" to achieve the perfect network sharing of public data and government information systems, giving priority to supporting the application of government data in urban construction and community home-based elderly care services, and accelerating the integrated development of the community home-based care industry model in the field of big data technology and fiscal finance and public services. The central and local governments of our country allocate financial funds to help communities build "smart medical care for the elderly", develop a modern medical service model based on medical big data, mobile medical care and elderly disease data, and achieve the controllable medical monitoring platform by interconnection and instant feedback. Through the allocation of human, material and financial resources, intelligently obtain data, data analysis and remote diagnosis and treatment services, comprehensively improve the treatment efficiency of patients, and optimize the medical service level of the doctors and nurses, and the entire community support for the elderly. With the help of Internet of Things technologies, the elderly patients, community medical staff, past medical records and medical services are connected by sensing components and smartphones, and the information of both patients and medical services is transmitted to the big data center of the community hospital in real time. Cloud computing technology quickly reads and analyzes the big data, and provides doctors with the best diagnosis and treatment plan, and also give patients the best medical advice, through intelligent scheduling services, comprehensive real-time data of community hospitals and large hospitals and patient condition analysis,. Older patients can get medical services conveniently and quickly at home, and thus the hospital's medical resources are effectively expanded to the scope of community medical services [13]. 


\section{Conclusion}

China's fiscal system has an impact on the effective supply of community home-based pension services. The local governments have not fully reflected the advantages that the fiscal system gives the local government on the reasonable adjustment and development of the scale and content of community home-based pension services, which makes the quality of community home-based pension services decline, shows a negative effect on the supply of community home-based elderly care services, and becomes the main institutional root of low efficiency. Under the current fiscal system of our country, if we want to improve the community home-based pension service, on the one hand, we should implement appropriate centralization to the finance, and transfer the fiscal expenditure responsibilities of community home-based elderly care from the local governments to their higher governments from the bottom up. On the other hand, we should give actively play to the organization and coordination function of the central government, improve the community home-based elderly care service in poor areas by using the central special transfer payment, and improve the negative impact caused by local government competitions. Let the community home-based elderly care service model become a better choice for the integration of equalization of public services provided by the government, satisfaction of the wills of old people, convenience, safety, quality and economy.

\section{References}

[1] Fu Yong. On Fiscal decentralization, Government Governance and Non-economic Public Goods Supply. Economic Research Journal, 2010 (8): 5.

[2] Han Junjiang, Wang Tianxin. Research on the Public Finance Supporting Social Pension Service in China, Social Security, 2015 (8): 49.

[3] Hu Hongwei, Shi Yuanyuan, Xiao Yixue. The Way and Path Choice of China's Pension Security from the Perspective of Equalization of Public Services-Advantages and Development Path of Home-based elderly care service guarantee. East China Economic Management, 2012 (1): 121-122.

[4] Notice on the Central fiscal Support to Carry out the Pilot Work of Home-based and Community-based Elderly Care Service Reform, Civil Letter [2016] No. 200.
[5] Cao Yuming, Cao Bo, Li Jing. The Model of Urban Community Support for the Elderly Cooperation and Co-govenance from the Perspective of Public Service Government_- Taking Xuanwu District of Nanjing as an Example. Journal of Huazhong Agricultural University (Social Sciences), 2013 (4): 115-116.

[6] Qiao Baoyun, Fan Jianyong, Feng Xingyuan. Fiscal Decentralization and Compulsory Primary Education in China. Social Sciences in China, 2005 (6): 39.

[7] Feng Gong, Lu Hongyou. Fiscal Decentralization and Local Public Service Allocation Efficiency: An Empirical Study Based on Compulsory Education and Medical and Health Services. Economic Review, 2013 (1): 48-49.

[8] Yu Changge. Analysis of the Mechanism of Chinese-style Fiscal Decentralization and Public Service Supply. Research on Financial and Economic Issues, 2008 (11): 86.

[9] Oates, W., “A Essay on Fiscal Federalism”, Journal of Economic Literatur, 1999 (37): p1120-1149.

[10] Gao Weimin. Marketization Bringing Benefits for Elderly Care Services. Anhui Economic News, Nov. 4, 2014, Edition 003.

[11] Zhuang Li. Research on Urban Pension Service System in China. Master's Thesis of Dongbei University of Finance and Economics, Nov. 2012: 10.

[12] Chen Yuzhuo. On the Operation of Community Home-based Pension Service Agencies. 16: 18: 43, Jan. 19, 2017, Xinhuanet.

[13] Hao Li, Zhang Weijian. Construction of "Health Care Pension - Insurance" Integrated smart Community Pension Model Based on Big Data. Chinese Journal of Gerontology, 2017 (1): 226-227.

\section{Biography}

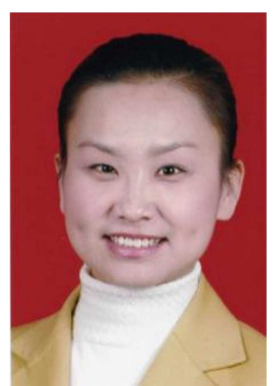

Shi Jing, female, was born in 1980, in Zhengzhou City, Henan Province, China. Since 2003, she had been studying modern logic with Professor $\mathrm{Na} \mathrm{Li}$, a famous logician in China. In 2009, she graduated from the school of philosophy of Nankai University with a Ph.D. and is now an associate professor of the School of Culture and Media of the Central University of Finance and Economics and a Master's Supervisor of Logic. Her main study field is in symbolic logic and philosophical Logic. 